Article

\title{
Antiplatelet Activity of Isorhamnetin via Mitochondrial Regulation
}

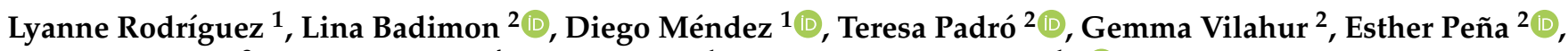 \\ Basilio Carrasco ${ }^{3}$, Hermine Vogel ${ }^{4}$, Iván Palomo ${ }^{1, *}$ and Eduardo Fuentes ${ }^{1, *(D)}$ \\ 1 Thrombosis Research Center, Department of Clinical Biochemistry and Immunohaematology, \\ Faculty of Health Sciences, Medical Technology School, Universidad de Talca, Talca 3460000, Chile; \\ lyannerodriguez89@gmail.com (L.R.); dmendez12@alumnos.utalca.cl (D.M.) \\ 2 Cardiovascular Program-ICCC and CiberCV, IR-Hospital de la Santa Creu i Sant Pau, \\ 08025 Barcelona, Spain; lbadimon@santpau.cat (L.B.); tpadro@santpau.cat (T.P.); gvilahur@santpau.cat (G.V.); \\ epena@santpau.cat (E.P.) \\ 3 Centro de Estudios en Alimentos Procesados, Talca 3460000, Chile; bcarrasco@ceap.cl \\ 4 CENATIV, Departamento de Horticultura, Facultad de Ciencias Agrarias, Universidad de Talca, \\ Talca 3460000, Chile; hvogel@utalca.cl \\ * Correspondence: ipalomo@utalca.cl (I.P.); edfuentes@utalca.cl (E.F.)
}

Citation: Rodríguez, L.; Badimon, L.; Méndez, D.; Padró, T.; Vilahur, G.;

Peña, E.; Carrasco, B.; Vogel, H.;

Palomo, I.; Fuentes, E. Antiplatelet Activity of Isorhamnetin via

Mitochondrial Regulation.

Antioxidants 2021, 10, 666. https://

doi.org/10.3390/antiox10050666

Academic Editor: Petr Ježek

Received: 18 March 2021

Accepted: 14 April 2021

Published: 25 April 2021

Publisher's Note: MDPI stays neutral with regard to jurisdictional claims in published maps and institutional affiliations.

Copyright: (c) 2021 by the authors. Licensee MDPI, Basel, Switzerland. This article is an open access article distributed under the terms and conditions of the Creative Commons Attribution (CC BY) license (https:/ / creativecommons.org/licenses/by/ $4.0 /)$.

\begin{abstract}
With the diet, we ingest nutrients capable of modulating platelet function, which plays a crucial role in developing cardiovascular events, one of the leading causes of mortality worldwide. Studies that demonstrate the antiplatelet and antithrombotic potential of bioactive compounds are vital to maintaining good cardiovascular health. In this work, we evaluate the flavonol isorhamnetin's antiplatelet effect on human platelets, using collagen, thrombin receptor activator peptide 6 (TRAP-6), and phorbol myristate acetate (PMA) as agonists. Isorhamnetin induced a significant inhibition on collagen- and TRAP-6-induced platelet aggregation, with half-maximum inhibitory concentration $\left(\mathrm{IC}_{50}\right)$ values of $8.1 \pm 2.6$ and $16.1 \pm 11.1 \mu \mathrm{M}$, respectively; while it did not show cytotoxic effect. Isorhamnetin reduced adenosine triphosphate levels (ATP) in platelets stimulated by collagen and TRAP-6. We also evidenced that isorhamnetin's antiplatelet activity was related to the inhibition of mitochondrial function without effect on reactive oxygen species (ROS) levels. Additionally, we investigated isorhamnetin's effect on thrombus formation in vitro under flow conditions on the damaged vessel wall. In this context, we demonstrate that isorhamnetin at $20 \mu \mathrm{M}$ induced a significant inhibition on platelet deposition, confirming its antithrombotic effect. Our findings corroborate the antiplatelet and antithrombotic potential of isorhamnetin present in many foods of daily consumption.
\end{abstract}

Keywords: isorhamnetin; flavonoids; antithrombotic; antiplatelet; foods

\section{Introduction}

The number of deaths from diet-related cardiovascular events increased between 2010 and 2016 [1]. With a healthy diet, rich mainly in fruits and vegetables, more than $30 \%$ of deaths could be prevented [2,3]. A balanced diet is vital to avoid premature death [1]. It is necessary to promote the concept of a healthy diet, a diet that includes the intake of minimally processed foods and it is rich in bioactive products present in fruits, beans, fish, seeds, whole grains, yogurt, nuts, vegetable oils, and vegetables [3]. Indeed, numerous investigations indicate that the dietary intake of flavonoids, such as quercetin and its derivatives present in fruits and vegetables, can reduce the risk of cardiovascular diseases (CVD) [4,5].

Isorhamnetin (3-methyl quercetin, molecular formula: $\mathrm{C}_{16} \mathrm{H}_{12} \mathrm{O}_{7}$ ) is a methylated flavonol present in leaves, flowers, and fruits of many plants [5-7]. This is the case of Phaseolus vulgaris L., belonging to the group of legume plants consumed in the five 
continents as an essential component of the diet [8]. These seeds have beneficial health properties due to the presence of polyphenolic compounds [9], of which flavonoids stand out, specifically isorhamnetin and its derivatives as isorhamnetin-3-glucoside [10] and isorhamnetin 3-glucuronide [11].

Epidemiological and clinical studies have shown that beans' consumption is inversely related to coronary artery diseases and the risk of cardiovascular events [12,13]. Various works showed that consuming beans four or more times per week reduces risks of coronary artery disease and CVD $[9,13]$. In addition, Phaseolus vulgaris L. has been related to the inhibition of thrombotic events. Even bean extracts reduced platelet aggregation stimulated by adenosine $5^{\prime}$-diphosphate (ADP) and arachidonic acid. The antiplatelet mechanism was related to activation of protein kinase B (AKT), which decreases the activation of platelets [8].

Isorhamnetin has been used in traditional medicine to prevent and treat various diseases $[14,15]$ due to its cardiovascular, anti-inflammatory, antitumor, antioxidant, antibacterial, antiviral, and anticoagulant activities $[5,6,16]$. The pharmacological effects of this flavonoid have been reported to be related to the regulation of activated $\mathrm{B}$ cell kappa light chain enhancer nuclear factor (NF-KB), PI3K/AKT, mitogen-activated protein kinases (MAPK), and other downstream signaling pathways [6].

In the context of cardioprotective potential, isorhamnetin protects against cardiac hypertrophy by blocking the PI3K-AKT pathway $[5,15]$. The effects on atherosclerosis in vitro and in vivo have also been evaluated [17]. Isorhamnetin was shown to inhibit atherosclerotic plaque development by activation of PI3K/AKT [17]. In addition, this compound reduces myocardial hypertrophy and fibrosis caused by pressure loading $[6,15]$.

A causal factor in cardiovascular disorders is platelet activation. Platelets play a fundamental role in thrombus formation, atherogenesis, and atherosclerotic lesions progression [18]. The inhibitions of platelet activation by natural products have been described as a central target to prevent thrombus formation $[19,20]$. Isorhamnetin can inhibit platelet aggregation, but the specific mechanisms have not yet been verified [6]. Consequently, our objective was to evaluate isorhamnetin's antiplatelet activity against different agonists and explore the specific mechanisms involved in the antiplatelet effects to provide further evidence of its healthy properties.

\section{Materials and Methods}

\subsection{Chemicals}

Thrombin 6 receptor activating peptide (TRAP-6), collagen, and phorbol myristate acetate (PMA), were obtained from Sigma-Aldrich (St. Louis, MO, USA). Antimycin (AA), citrate-dextrose solution, mepacrine, dihydroethidium (DHE), intracellular calcium fluorescence indicator (Fluo-3-AM), and trifluoromethoxyphenylhydrazone (FCCP) were also obtained from Sigma-Aldrich (St. Louis, MO, USA). FITC annexin V apoptosis, PE mouse IgG1 isotype control, and FITC mouse anti-human CD61 were obtained from BD Biosciences (San Diego, CA, USA). Isorhamnetin was obtained from Cayman Chemical, USA. All assays incorporated as vehicle control dimethyl sulfoxide (DMSO) $0.2 \%$.

\subsection{Preparation of Human Platelets}

Platelets were obtained from six healthy volunteers (men and women) who did not consume medication for two weeks. Donors signed the informed consent according to the protocol approved by the Scientific Ethics Committee of the University of Talca (protocol no. 19/2018), following the Declaration of Helsinki [21]. Blood was collected with acid-citratedextrose (ACD) 4:1 $v / v$ and then centrifuged at room temperature for $10 \mathrm{~min}$ at $240 \times g$ to obtain platelet-rich plasma (PRP). PRP was centrifuged $(800 \times g)$ at room temperature for $8 \mathrm{~min}$ [22]. Then platelet pellet was resuspended in calcium-free Tyrode's buffer: ACD $(5: 1 \mathrm{v} / \mathrm{v})$. The platelets were washed again by centrifugation at $800 \times g$ for $8 \mathrm{~min}$ [23]. The platelet count was performed on a hematology counter (Mindray BC-3000 Plus hematology counter, Shenzhen, China). Washed platelets were added to an Eppendorf, and anti-CD61- 
FITC was added. Thus, platelet purity ( $>99 \%)$ was confirmed by flow cytometry Accuri C6 (BD, Biosciences, San Jose, CA, USA) using an anti-CD61-FITC antibody (Supplementary Figure S1). Platelet populations were selected based on cell size using scatter (FSC) versus side scatter (SSC) and CD61 positivity to distinguish it from electronic noise, as described by other authors [22]. Flow cytometry experiments were controlled with PE mouse IgG1 isotype control [24].

\subsection{Cytotoxic Activity}

Washed platelets $\left(3 \times 10^{8}\right.$ platelets $\left./ \mathrm{mL}\right)$ were incubated with isorhamnetin $(10,50$ and $100 \mu \mathrm{M})$ for $10 \mathrm{~min}$ at $37^{\circ} \mathrm{C}$. Subsequently, platelets were centrifuged $(800 \times g)$ for $8 \mathrm{~min}$, and the supernatant was analyzed with the lactate dehydrogenase (LDH) cytotoxicity assay kit (Cayman Chemical, MI, USA). A microplate reader (Thermo Scientific Multiskan Go Microplate Reader, Vantaa, Finland) was used to measure the reaction's absorbance at $490 \mathrm{~nm}$. The positive control was Triton X-100 (10\%) [23].

\subsection{Platelet Aggregation Assay}

Inhibition of platelet aggregation was evaluated by a turbidimetric method using a lumi-aggregometer (Chrono-Log, Havertown, PA, USA) [25,26]. Washed platelets $\left(3 \times 10^{8}\right.$ platelets $\left./ \mathrm{mL}\right)$ were incubated for $5 \mathrm{~min}$ with $\mathrm{CaCl}_{2}(2 \mathrm{mM})$ plus isorhamnetin (1, $10,20,50$ and $100 \mu \mathrm{M}$ ) or vehicle (DMSO, $0.2 \%$ ). Similar concentrations in vitro have been evaluated in other studies [6,27]. Platelet aggregation was induced by TRAP-6 $(5 \mu \mathrm{M})$, collagen $(1 \mathrm{mg} / \mathrm{mL})$, and PMA $(100 \mathrm{nM})$. Platelet aggregation (transmittance) was measured for 6 min [23]. The platelet aggregation percentage was obtained with the AGGRO/LINK software (Chrono-Log, Havertown, PA, USA). Platelet inhibition was calculated as: inhibition of platelet aggregation $(\%)=100-(($ platelet aggregation of isorhamnetin/platelet aggregation of negative control $\times 100$ ) [28]. The concentration necessary to reduce platelet aggregation by $50 \%\left(\mathrm{IC}_{50}\right)$ was obtained from isorhamnetin's concentration curves $(1,10$, 20, 50, and $100 \mu \mathrm{M})$.

\subsection{Phosphatidylserine Externalization}

Externalization of phosphatidylserine (PS) in platelets was determined by flow cytometry, following the methodology described by Mendez et al. 2020, with slight modifications [23,29]. Washed platelets $\left(3 \times 10^{8}\right.$ platelets $\left./ \mathrm{mL}\right)$ were incubated for $5 \mathrm{~min}$ with $\mathrm{CaCl}_{2}$ $(2 \mathrm{mM})$ and subsequently with isorhamnetin $(1,10$, and $20 \mu \mathrm{M})$ for $10 \mathrm{~min}$ at $37^{\circ} \mathrm{C}$. In addition, PS was induced in activated conditions by collagen $(1 \mathrm{mg} / \mathrm{mL}) /$ TRAP- $6(5 \mu \mathrm{M})$. The samples were then diluted with annexin V-binding buffer and pre-incubated in the dark with annexin V-FITC and anti-CD61-PE for $30 \mathrm{~min}$. Samples were examined on an Accuri C6 flow cytometer (BD, Biosciences, San Jose, CA, USA).

\subsection{Platelet Secretion (Extracellular ATP)}

Extracellular adenosine triphosphate (ATP) was determined using Chrono-lume (ChronoLog, Havertown, PA, USA) [22]. Washed platelets $\left(3 \times 10^{8}\right.$ platelets $\left./ \mathrm{mL}\right)$ were incubated for 5 min with $\mathrm{CaCl}_{2}(2 \mathrm{mM})$ and isorhamnetin $(1,10$ and $20 \mu \mathrm{M})$. The luciferin (ChronoLume) reagent and the platelet agonists (TRAP- $65 \mu \mathrm{M}$ and collagen $1 \mu \mathrm{g} / \mathrm{mL}$ ) were added consecutively. ATP secretion (100\%) was obtained with the vehicle (DMSO $0.2 \%$ ) plus the platelet agonists. Adenosine $(10 \mu \mathrm{M})$ was used as a positive control of inhibition.

\subsection{Intracellular Calcium Levels}

Washed platelets $\left(3 \times 10^{8}\right.$ platelets $\left./ \mathrm{mL}\right)$ were incubated with Fluo-3-AM $(0.4 \mu \mathrm{M})$ at room temperature for $30 \mathrm{~min}$ as previously described by Mendez et al. 2020 [23]. Subsequently, platelets were diluted $\left(5 \times 10^{7}\right.$ platelets $\left./ \mathrm{mL}\right)$ with Tyrode's buffer without calcium, and the samples were incubated with the negative control, FCCP $(1 \mu \mathrm{M})$ or isorhamnetin $(1,10$ and $20 \mu \mathrm{M})$ for $10 \mathrm{~min}$ at $37^{\circ} \mathrm{C}$. The effect of isorhamnetin on the 
intracellular calcium levels was calculated relative to the vehicle (DMSO 0.2\%) using the Accuri C6 flow cytometer (BD, Biosciences, San Jose, CA, USA).

\subsection{Reactive Oxygen Species}

Reactive oxygen species production (ROS) was determined in washed platelets $\left(5 \times 10^{7}\right.$ platelets $\left./ \mathrm{mL}\right)$ with DHE $(10 \mu \mathrm{M})$ in the presence of isorhamnetin $(1,10$, and $20 \mu \mathrm{M})$ and $\mathrm{CaCl}_{2}(2 \mathrm{mM})$ for $30 \mathrm{~min}$ at $37^{\circ} \mathrm{C}$. Antimycin $10 \mu \mathrm{M}$ was a positive control. ROS formation was analyzed by Accuri C6 flow cytometer (BD, Biosciences, San Jose, CA, USA) $[23,30]$.

\subsection{Mitochondrial Membrane Potential}

Mitochondrial membrane potential $(\Delta \psi \mathrm{m})$ was assessed with the permeating cellular dye tetramethylrhodamine methyl ester perchlorate (TMRM) as before described [23]. $\mathrm{CaCl}_{2}(2 \mathrm{mM})$ was added to the washed platelets $\left(5 \times 10^{7}\right.$ platelets $\left./ \mathrm{mL}\right)$. Then, TMRM $(100 \mathrm{nM})$ was added and incubated with DMSO $0.2 \%$, isorhamnetin $(1,10$, and $20 \mu \mathrm{M})$, or FCCP $1 \mu \mathrm{M}$ at $37^{\circ} \mathrm{C}$ for $30 \mathrm{~min}$. The samples were studied in the Accuri $\mathrm{C} 6$ flow cytometer (BD, Biosciences, San Jose, CA, USA) [31].

\subsection{Thrombosis under Flow Conditions on a Damaged Vascular Wall: The Badimon Perfusion Chamber}

The effect of isorhamnetin $(20 \mu \mathrm{M})$ on platelet adhesion and thrombus formation was evaluated under controlled blood flow conditions in the Badimon Perfusion Chamber [32,33]. The procedures used were reviewed and approved by the Institutional Committees for Animal Use and Care (CEEA-IR) and authorized by the Animal Experimental Committee of the local government (\#5601) following Spanish law (RD 53/2013) and European Directive 2010/63/EU. The research conforms to the Guide for the Care and Use of Laboratory Animals published by the US National Institutes of Health (NIH Publication no. 85-23, revised 1985) and follows the ARRIVE guidelines [34]. Pig aorta specimens fresh were obtained from a local slaughterhouse. The sample is immediately washed in PBS, cleaned of the adventitia, cut into long pieces, and then frozen at $-80^{\circ} \mathrm{C}$ until needed. The aortas were thawed in phosphate-buffered saline at $4{ }^{\circ} \mathrm{C}$, open longitudinally, and cut into $30 \times 10 \mathrm{~mm}$ segments. Aorta substrates were stripped of the intimal layer to expose the underlying thrombogenic medial layer and were mounted in the previously characterized Badimon perfusion chamber. Chambers were placed in series, each containing a piece of the porcine aorta. Porcine arterial blood was collected from healthy untreated animals in citrate-dextrose solution. Platelets were rendered fluorescent by the addition of mepacrine $20 \mu \mathrm{M}$. Blood was perfused over the damaged arterial wall place in the Badimon perfusion chamber. Aorta segments were washed with saline buffer and scrapped to recover adherent platelets. Platelets were resuspended in saline buffer $(500 \mu \mathrm{L})$ and frozen until use. Finally, platelet lysate fluorescence was measured in a Wallac 1420 Victor2 microplate reader (PerkinElmer). Platelet number was calculated from a standard curve $\left(\mathrm{n}^{\circ}\right.$ platelets vs. fluorescence; 2-fold platelet dilution series), plotting the mean absorbance for each standard against the platelet number on the $y$-axis. The data were linearized, and regression analysis was calculated $\left(y=15,114 x ; r^{2}=0.85\right)$.

\subsection{Statistical Analysis}

Data were represented as the mean \pm standard error of the mean (SEM) of the experiments and were analyzed using Prism 6.0 software (GraphPad Inc., San Diego CA, USA). The $\mathrm{IC}_{50}$ was calculated from the dose-response curves of isorhamnetin. Results were examined by analysis of variance (ANOVA) and Tukey's post hoc test to determine the significant differences between samples [2]. Differences between the two groups were analyzed by Student's $t$-test. $p$ values $<0.05$ were considered statistically significant. 


\section{Results}

\subsection{Cytotoxic Activity on Platelets}

LDH is released from the cell because of damage or lysis. In this context, isorhamnetin's cytotoxic effects were evaluated at 10,50 , and $100 \mu \mathrm{M}$. It was observed that isorhamnetin at none of the concentrations evaluated induced cytotoxic activity (Figure 1A). The PS externalization assay allows us to assess whether the compound under study (isorhamnetin) alters cell viability. We evaluated the levels of PS related to early apoptosis at different concentrations of isorhamnetin $(1,10$, and $20 \mu \mathrm{M})$. The PS was found to be unchanged in the presence of the isorhamnetin (Figure 1B).

A

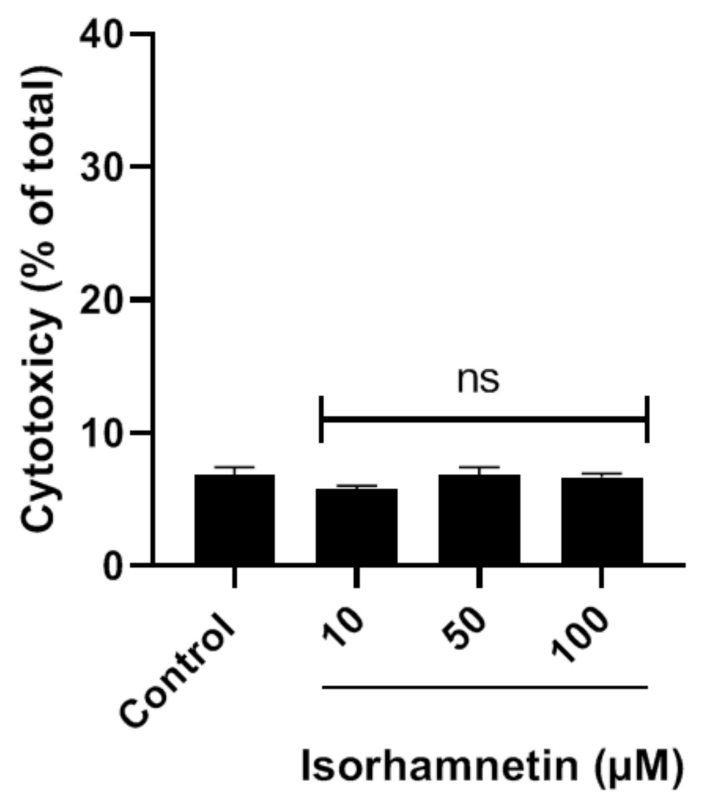

B

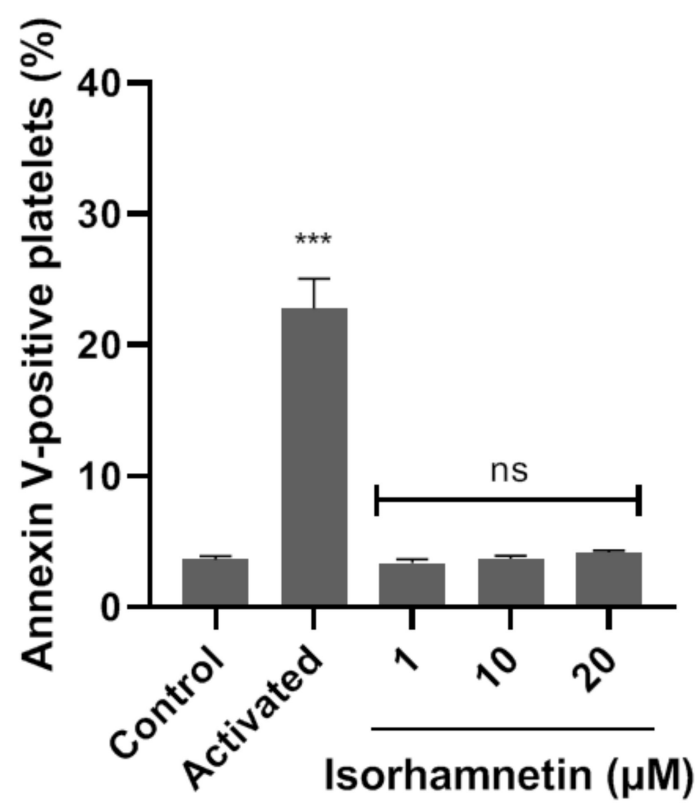

Figure 1. Evaluation of the cytotoxicity of isorhamnetin in washed platelets. (A) Effect of isorhamnetin on lactate dehydrogenase (LDH) release. (B) Effect of isorhamnetin on PS was evaluated by annexin V-binding in platelets. Activated is collagen/TRAP-6-induced externalization of PS. The results are shown as the mean \pm SEM of $n=3$. Control was DMSO $0.2 \%$. ${ }^{* * *} p<0.001$ vs., control. ns: not significant. PS: phosphatidylserine.

\subsection{Inhibition of Platelet Aggregation by Isorhamnetin}

The efficacy of isorhamnetin $(1,10,20,50$, and $100 \mu \mathrm{M})$ to inhibit platelet aggregation was evaluated by turbidimetry stimulated by collagen $(1 \mu \mathrm{g} / \mathrm{mL})$, TRAP-6 $(5 \mu \mathrm{M})$, and PMA (100 nM) (Figure 2A-C). The representative curves showed the dose-dependent to its platelet antiaggregant activity (Figure 2D-F). Isorhamnetin showed differences in its selectivity to inhibit platelet aggregation induced by platelet agonists. It showed more selectivity when platelets were activated with collagen and TRAP-6. Isorhamnetin (IC 50 of $8.1 \pm 2.6 \mu \mathrm{M}$ ) had a powerful concentration-dependent antiplatelet effect when platelet aggregation was induced by collagen. When TRAP- 6 was used as an agonist, the compound inhibited platelet aggregation with $\mathrm{IC}_{50}$ of $16.1 \pm 11.1 \mu \mathrm{M}$. While PMA-induced platelet aggregation had a lower activity $\left(\mathrm{IC}_{50}>100 \mu \mathrm{M}\right)$ and at $100 \mu \mathrm{M}$ inhibited PMA-induced platelet aggregation by about $30 \pm 6 \%$. Based on these results, we decided to continue the antiplatelet studies with isorhamnetin 1, 10, and $20 \mu \mathrm{M}$. 


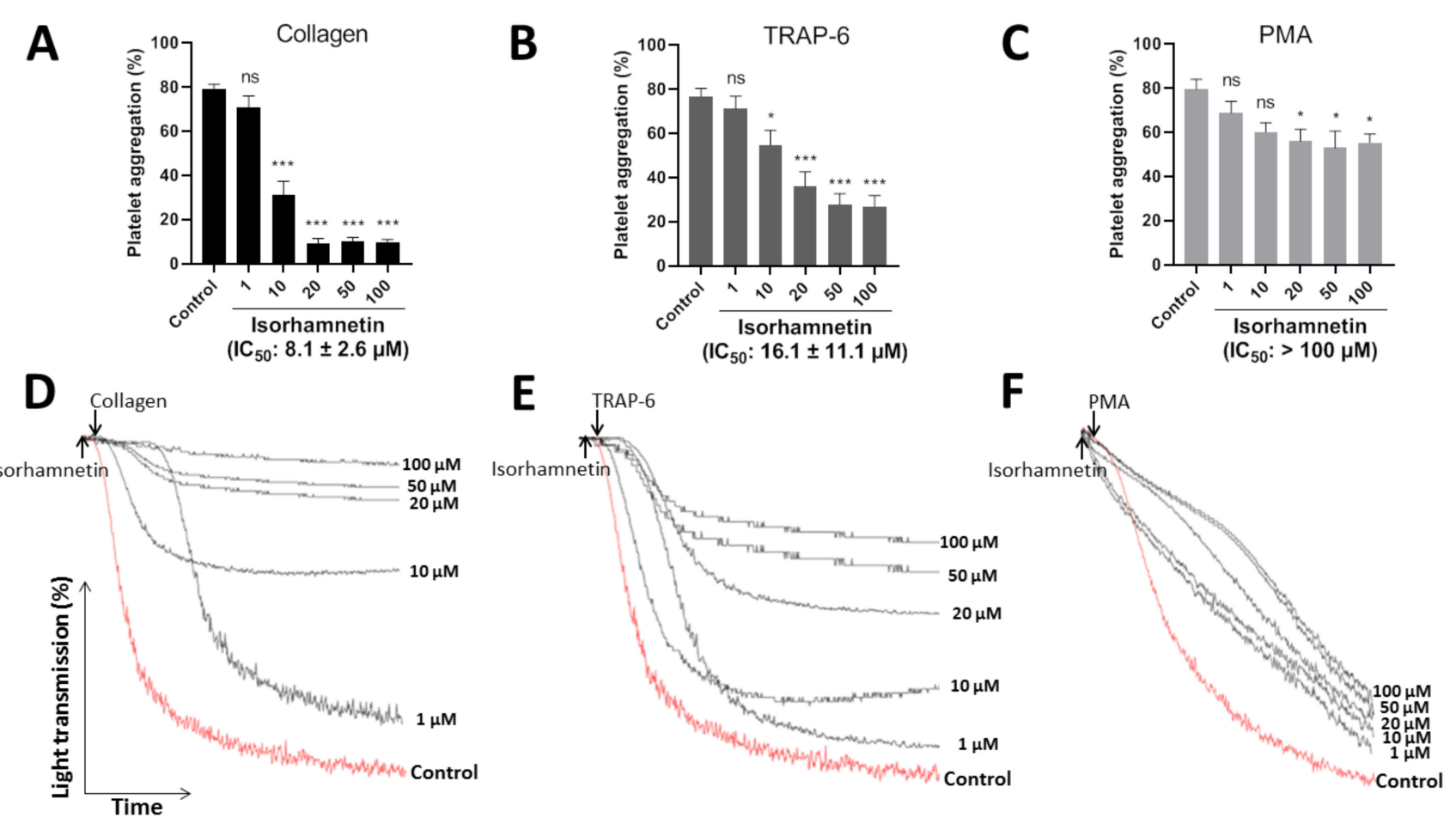

Figure 2. Inhibitory effect of isorhamnetin on platelet aggregation induced by collagen, TRAP-6, and PMA. (A) Platelet aggregation induced by collagen. (B) Platelet aggregation induced by TRAP-6. (C) Platelet aggregation induced by PMA. In this condition, isorhamnetin at $100 \mu \mathrm{M}$ inhibited PMA-induced platelet aggregation by about $30 \pm 6 \%$. (A-C) The results are shown as the mean \pm SEM of $n=6$. IC $_{50}$ was obtained from dose-response curves. (D-F) Representative curves of platelet aggregation induced by collagen, TRAP-6, and PMA. ${ }^{*} p<0.05,{ }^{* * *} p<0.001$ and ns (not significant) vs., control (DMSO 0.2\%). PMA: phorbol myristate acetate, TRAP-6: thrombin receptor activator peptide 6.

\subsection{Isorhamnetin Antiplatelet Mechanism}

\subsubsection{Platelet Secretion: Extracellular ATP}

Platelet activation is stimulated by platelet secretion products, such as ATP. About the control, isorhamnetin at $20 \mu \mathrm{M}$ lowers ATP levels to $0.28 \pm 0.03$ and $0.28 \pm 0.05$ (folds of control) in collagen- and TRAP-6-stimulated platelet, respectively (Figure 3A). Meanwhile, adenosine $(10 \mu \mathrm{M})$ about control decreased ATP levels to $0.20 \pm 0.05$ and $0.19 \pm 0.06$ (folds of control) in platelets stimulated by collagen and TRAP-6, respectively.

\subsubsection{Mitochondrial Membrane Potential}

The association between developing CVD and mitochondrial damage is well-known. We study if the isorhamnetin has an antiplatelet activity through the inhibition of mitochondrial bioenergetics. In this context, we observed that isorhamnetin at 1, 10, and $20 \mu \mathrm{M}$ significantly decreases the membrane potential compared to the control (Figure 3B).

\subsubsection{Reactive Oxygen Species (ROS)}

Platelet activation is regulated by the endogenous generation of ROS induced by a wide variety of stimuli, for example, at the mitochondrial level by antimycin $\mathrm{A}$. In our study, isorhamnetin was shown not to affect ROS (Figure 3C). 

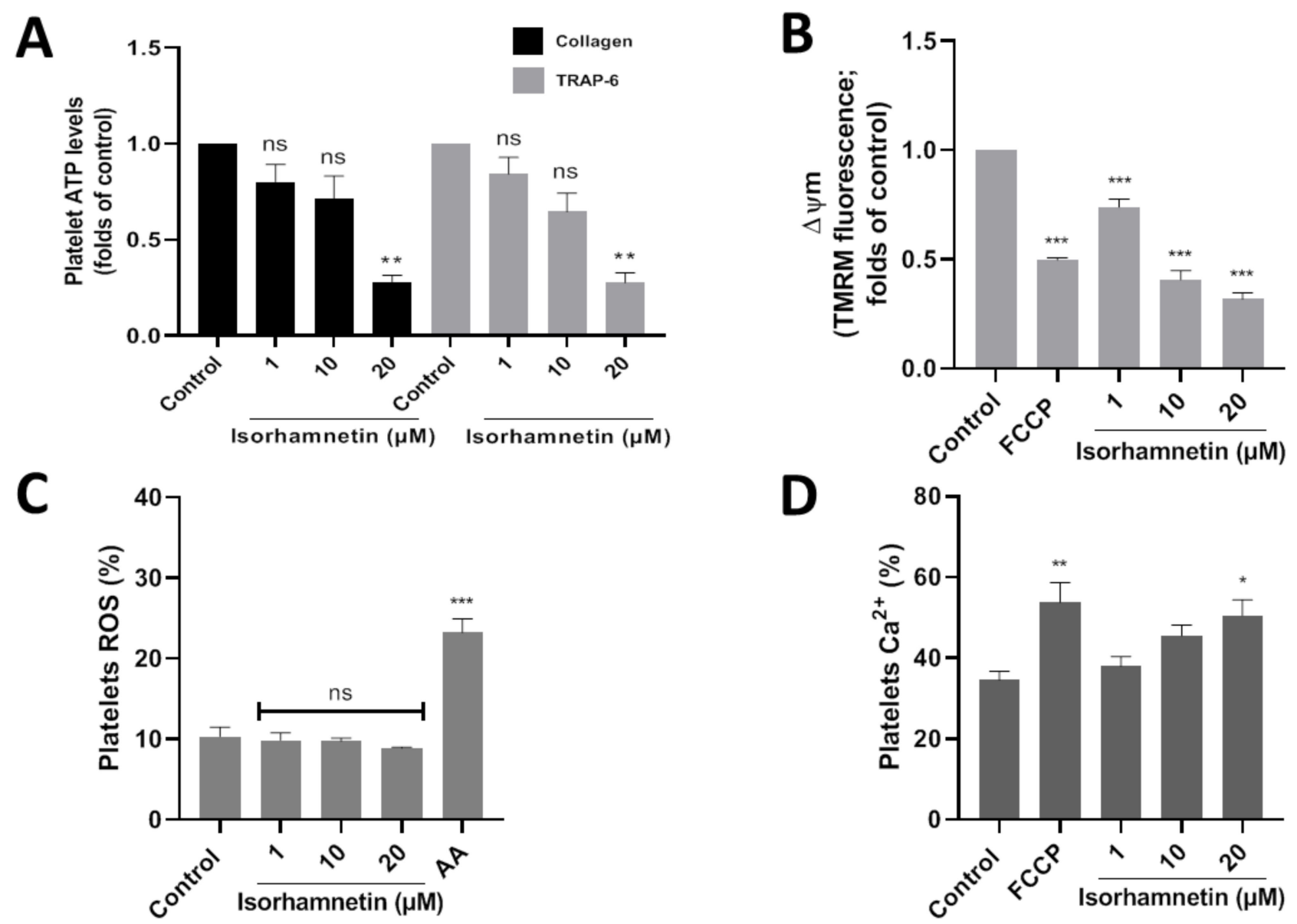

Figure 3. Evaluation of the antiplatelet mechanism of isorhamnetin. (A) Platelet ATP secretion stimulated by TRAP-6 or collagen in the presence of isorhamnetin. (B) Mitochondrial membrane potential $(\triangle \Psi \mathrm{m})$. (C) Levels of platelets ROS. (D) Levels of platelets calcium levels. The results are shown as the mean \pm SEM of $n=3 .{ }^{*} p<0.05,{ }^{* *} p<0.01,{ }^{* * *} p<0.001$ and ns (not-significant) vs., control (DMSO 0.2\%). AA: antimycin A $10 \mu \mathrm{M}$, ATP: adenosine triphosphate, FCCP: carbonyl cyanide-4- (trifluoromethoxy) phenylhydrazone, ROS: reactive oxygen species, TRAP-6: thrombin receptor activator peptide 6 .

\subsubsection{Intracellular Calcium Levels}

We assess whether our compound can modulate calcium levels in platelets. Isorhamnetin at $20 \mu \mathrm{M}$ was shown to increase $\mathrm{Ca}^{2+}$ levels relative to baseline (Figure 3D). Isorhamnetin increases the release of calcium from dense granules; this is a response mechanism because the compound has been shown to decrease the membrane potential in the mitochondria.

\subsubsection{Thrombosis under Flow Conditions on a Vascular Wall (Badimon Perfusion Chamber)}

The Badimon chamber allowed us to evaluate isorhamnetin's effects on platelet deposition and thrombus formation caused by damaged vessel wall under low and high shear rate conditions. Isorhamnetin induced inhibitory effects at a low shear rate (typical of large arteries, such as the aorta) and at high shear rate (typical of smaller arteries, as the coronaries with stenosis). Isorhamnetin at $20 \mu \mathrm{M}$ induced a significant reduction in platelet deposition versus an untreated blood sample (Figure 4) at both shear conditions. The data confirm the antithrombotic effect of isorhamnetin on thrombus triggered by a biological vascular substrate and prothrombotic flow conditions mimicking arteries perfused by blood at high shear stress. 


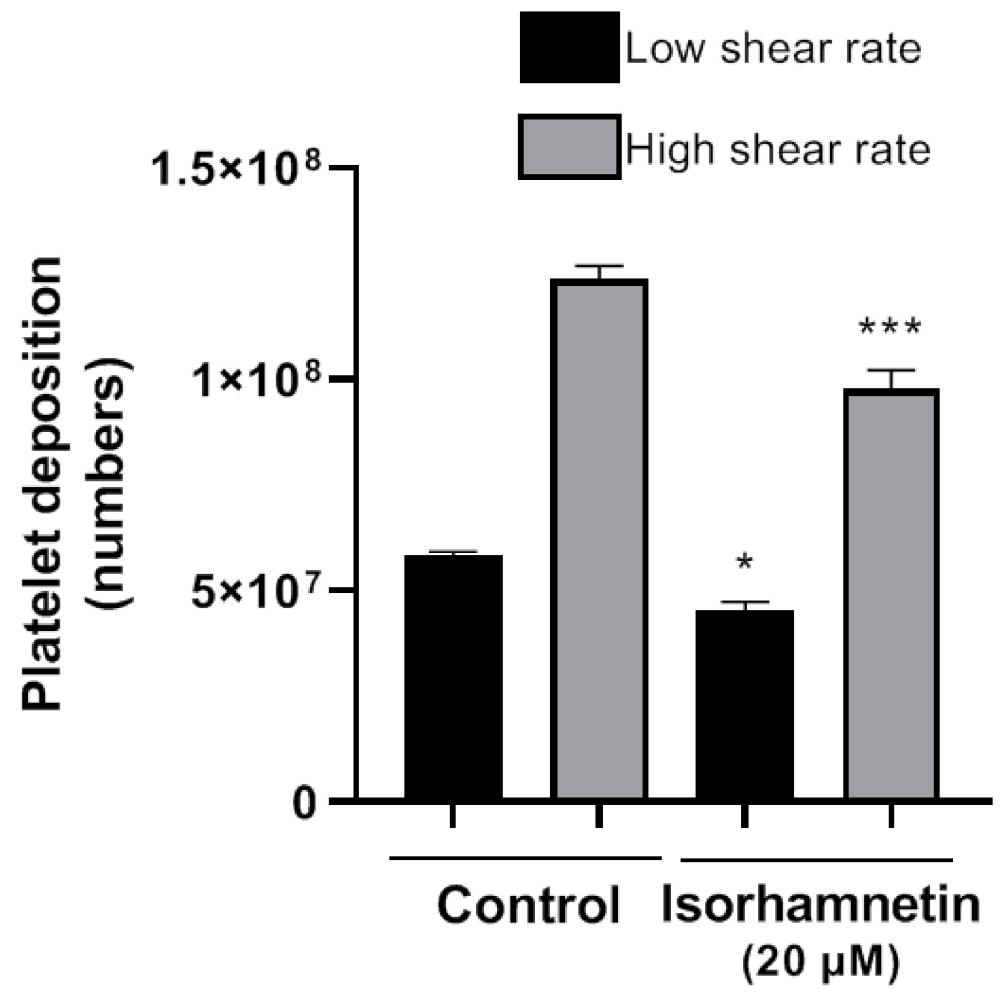

Figure 4. Effect of isorhamnetin on thrombus formation in vitro under low and high shear rate conditions. The results are shown as the mean \pm SEM of $n=4 .{ }^{*} p<0.05$ and ${ }^{* * *} p<0.001$ vs., control (DMSO 0.2\%).

\section{Discussion}

Platelets are the smallest blood cells, and their activation at sites of the vascular lesion is essential for thrombus formation [35]. The treatment to prevent thrombosis associated with platelet activation requires the inhibition of platelet activation [36]. Aspirin and clopidogrel are essential in managing platelet aggregation, but several patients continue to suffer from recurrent thrombotic problems and even can induce bleeding [37]. That is why finding potential antiplatelet agents in foodstuff used daily with the diet would represent a clear advantage to reduce the challenge of thrombotic risk. In this context, it is vital to promote adequate nutrition in the population by consuming fruits and vegetables, to achieve a healthy lifestyle [8]. Different investigations show that the intake of flavonoids present in vegetables and fruits can reduce CVD, modulating platelet activation [18].

Isorhamnetin has broad pharmacological effects, such as anti-osteoporosis [38], antiinflammatory [39], antioxidants [40], anti-apoptosis [17], immune regulatory [41], and other pharmacological effects for which the mechanisms of action have been described. Therefore, in this article, we have investigated its antiplatelet potential and the mechanisms involved, contributing to generating the evidence necessary for future in vivo studies.

LDH activity can be used as an indicator of cell membrane integrity and, therefore, a measure of cytotoxicity [35]. Isorhamnetin cytotoxicity levels were evaluated by measuring cytosolic LDH release without observing any platelet damage. In addition, isorhamnetin did not affect PS exposure, a modification in platelets associated with mitochondrial apoptotic-like events [42,43], confirming non-cytotoxic effects on platelets. We used light transmission aggregometry to evaluate the inhibitory activity of isorhamnetin (1 to $100 \mu \mathrm{M})$ in platelet aggregation induced by collagen, TRAP-6, and PMA. Similar concentrations have been studied to evaluate isorhamnetin's protective effect and its derivatives [27,44-46].

Platelet agonists activate different pathways in signal transductions. TRAP-6 acts as a PAR1 agonist in platelet activation [35,47]; glycoprotein VI (GPVI) is the primary collagen receptor in platelet activation. On the other hand, integrin $\alpha 2 \beta 1$ and CD36 bind directly 
to collagen, while subunits of the GP Ib-IX complex (GP) Ib $\alpha$ and integrin $\alpha \mathrm{IIb} \beta 3$ interact with von Willebrand factor (vWF) bound to collagen $[35,48]$. Isorhamnetin inhibited, in a dose-dependent manner, platelet aggregation induced by TRAP-6 and collagen. Our results suggest that isorhamnetin inhibited the platelet GPVI-mediated signaling pathway [42,49]. Ingestion of isorhamnetin-rich onion soup has been reported to inhibit collagen-stimulated platelet aggregation [6,50]. Conversely, isorhamnetin did not inhibit platelet aggregation stimulated by protein kinase C (PKC) agonist as PMA, suggesting that isorhamnetin acts upstream of PKC. Compounds, such as amyrins, have been reported to disrupt MAPK and arachidonic acid metabolisms, related to inhibition of upstream PKC targets [51,52].

Mitochondria via ATP production are involved as central drivers in platelet activation. In this context, inhibition of mitochondrial function has been reported as an antiplatelet target via a decrease of ATP levels [53,54]. We decided to evaluate whether isorhamnetin has antiplatelet activity by inhibiting mitochondrial function. This compound at $20 \mu \mathrm{M}$ causes a decrease of membrane potential without affecting ROS levels and decreasing ATP levels. In addition, due to isorhamnetin's action on the mitochondria, an increase in intraplatelet calcium levels was observed. These results show that isorhamnetin decreased platelet activation via inhibition of mitochondrial function, which is associated with potent non-selective inhibition of platelet aggregation induced by TRAP- 6 and collagen.

It has been described that atherothrombosis is initiated by collagen exposure when endothelial damage occurs, and this triggering platelet activation/adhesion [42,55]. In this context, we investigated the effects of isorhamnetin on thrombosis on vascular damage under flow conditions. We showed that this compound inhibited thrombus formation triggered by exposure of a highly thrombogenic surface to flowing blood (Badimon chamber).

Although this study has some limitations since the effects of isorhamnetin on platelet aggregation are more complex in vivo conditions, our results support scientific evidence that isorhamnetin helps reduce platelet activation and thereby thrombotic and cardiovascular risk.

\section{Conclusions}

Diet and nutrition influence the progression and/or treatment of CVD. Isorhamnetin may be a promising scaffold compound to develop new antiplatelet agents with specific action on thrombotic diseases. Isorhamnetin did not induce cytotoxic effects. Its antiplatelet potential was significant in collagen-stimulated platelet aggregation. Consecutively, it induced a fall in membrane potential and a decrease in ATP levels. The evidence presented in this work suggests that this flavonoid may play an important role in health maintenance and possibly protect against cardiovascular disease associated with the inhibition of platelet function and a possible reduction in the risk of thrombosis. Certainly, future studies, such as absorption and metabolism, are needed to translate the antiplatelet activity of in vitro dose-response to in vivo concentrations (human).

Supplementary Materials: The following are available online at https:/ / www.mdpi.com/article/10 .3390 /antiox10050666/s1, Figure S1: Representative dot plots of CD61+ (platelets).

Author Contributions: L.R.: investigation, formal analysis, writing-original draft preparation; L.B.: formal analysis, writing — reviewing and editing, and supervision; D.M.: investigation and formal analysis; T.P.: formal analysis and investigation; G.V.: formal analysis and investigation; E.P.: investigation; B.C.: writing-reviewing and editing; H.V.: writing-reviewing and editing; E.F.: conceptualization, writing - reviewing and editing, and supervision; I.P.: conceptualization and supervision. All authors have read and agreed to the published version of the manuscript.

Funding: This research was funded by Centro de Estudios en Alimentos Procesados-CEAP, ANID, Programa Regional R20F0001, Talca, Chile.

Institutional Review Board Statement: The study was conducted according to the guidelines of the Declaration of Helsinki, and approved by the Scientific Ethics Committee of University of Talca (protocol no. 19/2018). 
Informed Consent Statement: Informed consent was obtained from all subjects involved in the study.

Data Availability Statement: Data is contained within the article and supplementary material.

Acknowledgments: We appreciate the support of Centro de Estudios en Alimentos ProcesadosCEAP, ANID, Programa Regional R20F0001, Talca, Chile. Furthermore, thanks to the ANID-National Doctorate Scholarship (Folio: 21191143) and ANID R19A10001. LB, GV, TP and EP are funded by CiberCV, Institute Carlos III, Spain and Fundacion de Investigación Cardiovascular-Fundación Jesus Serra, Spain.

Conflicts of Interest: The authors declare no conflict of interest.

$\begin{array}{ll}\text { Abbreviations } \\ \text { AA } & \text { Antimycin } \\ \text { ADP } & \text { Adenosine diphosphate } \\ \text { ACD } & \text { Acid-citrate-dextrose } \\ \text { AKT } & \text { Protein kinase B } \\ \text { ANOVA } & \text { Analysis of variance } \\ \text { ATP } & \text { Adenosine triphosphate } \\ \text { CDV } & \text { Cardiovascular diseases } \\ \text { DHE } & \text { Dihydroethidium } \\ \text { DMSO } & \text { Dimethyl sulfoxide } \\ \text { ERK } \frac{1}{2} & \text { Extracellular signal-regulated kinases 1/2 } \\ \text { FCCP } & \text { Carbonylcyanide p-trifluoromethoxyphenylhydrazone } \\ \text { FITC } & \text { Fluorescein-5-isothiocyanate } \\ \text { Fluo-3-AM } & \text { Intracellular calcium fluorescence indicator } \\ \text { FSC } & \text { Forward scatter } \\ \text { GP Ib } \alpha & \text { Subunits of the GP Ib-IX complex } \\ \text { GPVI } & \text { Glycoprotein VI or glycoprotein receptor for collagen } \\ \text { IC } 50 & \text { Half-maximum inhibitory concentration } \\ \text { LDH } & \text { Lactate dehydrogenase } \\ \text { MAPK } & \text { Mitogen-activated protein kinases } \\ \triangle \Psi \mathrm{W} & \text { Mitochondrial membrane potential } \\ \text { NF- } \mathrm{B} B & \text { Activated B cell kappa light chain enhancer nuclear factor } \\ \text { PAR1 } & \text { Protease-activated receptor-1 } \\ \text { PI3K } & \text { Phosphatidylinositol-3-kinase } \\ \text { PKC } & \text { Protein kinase C } \\ \text { PMA } & \text { Phorbol myristate acetate } \\ \text { PRP } & \text { Platelet-rich plasma } \\ \text { PS } & \text { Phosphatidylserine } \\ \text { ROS } & \text { Reactive oxygen species } \\ \text { SEM } & \text { Standard error of the mean } \\ \text { SSC } & \text { Side scatter } \\ \text { TMRM } & \text { Tetramethylrhodamine methyl ester perchlorate } \\ \text { TRAP-6 } & \text { Thrombin receptor activator peptide 6 } \\ \text { vWF } & \text { Von Willebrand factor } \\ & \end{array}$

\section{References}

1. Meier, T.; Gräfe, K.; Senn, F.; Sur, P.; Stangl, G.I.; Dawczynski, C.; März, W.; Kleber, M.E.; Lorkowski, S. Cardiovascular mortality attributable to dietary risk factors in 51 countries in the WHO European Region from 1990 to 2016: A systematic analysis of the Global Burden of Disease Study. Eur. J. Epidemiol. 2019, 34, 37-55. [CrossRef] [PubMed]

2. Alarcón, M.; Bustos, M.; Mendez, D.; Fuentes, E.; Palomo, I.; Lutz, M. In vitro assay of quinoa (chenopodium quinoa willd) and lupin (lupinus spp.) Extracts on Human Platelet Aggregation. Plant Foods Hum. Nut. 2020, 1-8. [CrossRef] [PubMed]

3. Lutz, M.; Fuentes, E.; Ávila, F.; Alarcón, M.; Palomo, I. Roles of phenolic compounds in the reduction of risk factors of cardiovascular diseases. Molecules 2019, 24, 366. [CrossRef]

4. Eccleston, C.; Baoru, Y.; Tahvonen, R.; Kallio, H.; Rimbach, G.H.; Minihane, A.M. Effects of an antioxidant-rich juice (sea buckthorn) on risk factors for coronary heart disease in humans. J. Nut. Biochem. 2002, 13, 346-354. [CrossRef] 
5. Skalski, B.; Lis, B.; Pecio, Ł.; Kontek, B.; Olas, B.; Żuchowski, J.; Stochmal, A. Isorhamnetin and its new derivatives isolated from sea buckthorn berries prevent $\mathrm{H}_{2} \mathrm{O}_{2} / \mathrm{Fe}-$ Induced oxidative stress and changes in hemostasis. Food Chem. Toxicol. 2019, 125, 614-620. [CrossRef]

6. Gong, G.; Guan, Y.-Y.; Zhang, Z.-L.; Rahman, K.; Wang, S.-J.; Zhou, S.; Luan, X.; Zhang, H. Isorhamnetin: A review of pharmacological effects. Biomed. Pharmacother. 2020, 128, 110301. [CrossRef]

7. Lu, X.; Liu, T.; Chen, K.; Xia, Y.; Dai, W.; Xu, S.; Xu, L.; Wang, F.; Wu, L.; Li, J. Isorhamnetin: A hepatoprotective flavonoid inhibits apoptosis and autophagy via P38/PPAR- $\alpha$ pathway in mice. Biomed. Pharmacother. 2018, 103, 800-811. [CrossRef] [PubMed]

8. Rodríguez-Azúa, R.; Quinteros, E.F.; Olate-Briones, A.; Moore-Carrasco, R. Phaseolus vulgaris exerts an inhibitory effect on platelet aggregation through AKT dependent way. Prev. Nut. Food Sci. 2018, 23, 102. [CrossRef]

9. Ganesan, K.; Xu, B. Polyphenol-rich dry common beans (Phaseolus vulgaris L.) and their health benefits. Int. J. Mol. Sci. 2017, 18, 2331. [CrossRef]

10. Sidorova, Y.; Shipelin, V.; Mazo, V.; Zorin, S.; Petrov, N.; Kochetkova, A. Hypoglycemic and hypolipidemic effect of Vaccinium myrtillus L. leaf and Phaseolus vulgaris L. seed coat extracts in diabetic rats. Nutrition 2017, 41, 107-112. [CrossRef]

11. Abu-Reidah, I.M.; Arráez-Román, D.; Lozano-Sánchez, J.; Segura-Carretero, A.; Fernández-Gutiérrez, A. Phytochemical characterisation of green beans (Phaseolus vulgaris L.) by using high-performance liquid chromatography coupled with time-of-flight mass spectrometry. Phytochem. Anal. 2013, 24, 105-116. [CrossRef]

12. Finley, J.W.; Burrell, J.B.; Reeves, P.G. Pinto bean consumption changes SCFA profiles in fecal fermentations, bacterial populations of the lower bowel, and lipid profiles in blood of humans. J. Nutr. 2007, 137, 2391-2398. [CrossRef]

13. Winham, D.M.; Hutchins, A.M. Baked bean consumption reduces serum cholesterol in hypercholesterolemic adults. Nutr. Res. 2007, 27, 380-386. [CrossRef]

14. Park, J.C.; Young, H.S.; Yu, Y.B.; Lee, J.H. Isorhamnetin sulphate from the leaves and stems of Oenanthe javanica in Korea. Planta Med. 1995, 61, 377-378. [CrossRef] [PubMed]

15. Gao, L.; Yao, R.; Liu, Y.; Wang, Z.; Huang, Z.; Du, B.; Zhang, D.; Wu, L.; Xiao, L.; Zhang, Y. Isorhamnetin protects against cardiac hypertrophy through blocking PI3K-AKT pathway. Mol. Cell. Biochem. 2017, 429, 167-177. [CrossRef]

16. Teng, D.; Luan, X. Research progress of isorhamnetin in pharma codynamics. Clin. J. Tradit. Chin. Med. 2016, 28, 593-596.

17. Luo, Y.; Sun, G.; Dong, X.; Wang, M.; Qin, M.; Yu, Y.; Sun, X. Isorhamnetin attenuates atherosclerosis by inhibiting macrophage apoptosis via PI3K/AKT activation and HO-1 induction. PLoS ONE 2015, 10, e0120259. [CrossRef] [PubMed]

18. Olas, B. The multifunctionality of berries toward blood platelets and the role of berry phenolics in cardiovascular disorders. Platelets 2017, 28, 540-549. [CrossRef]

19. Yeung, J.; Holinstat, M. Newer agents in antiplatelet therapy: A review. J. Blood Med. 2012, 3, 33.

20. Mendez, D.; Arauna, D.; Fuentes, F.; Araya-Maturana, R.; Palomo, I.; Alarcon, M.; Sebastian, D.; Zorzano, A.; Fuentes, E. Mitoquinone (MitoQ) inhibits platelet activation steps by reducing ros levels. Int. J. Mol. Sci. 2020, 21, 6192. [CrossRef]

21. Pp, R. Human experimentation. Code of ethics of the world medical association. Declaration of Helsinki. Br. Med. J. 1964, 2, 177.

22. Fuentes, E.; Badimon, L.; Caballero, J.; Padro, T.; Vilahur, G.; Alarcon, M.; Pérez, P.; Palomo, I. Protective mechanisms of adenosine 5'-monophosphate in platelet activation and thrombus formation. Thromb. Haemost. 2014, 111, 491-507. [CrossRef] [PubMed]

23. Monroy-Cárdenas, M.; Méndez, D.; Trostchansky, A.; Martínez-Cifuentes, M.; Araya-Maturana, R.; Fuentes, E. Synthesis and Biological Evaluation of Thio-Derivatives of 2-Hydroxy-1,4-Naphthoquinone (Lawsone) as Novel Antiplatelet Agents. Front. Chem. 2020, 8, 1-9. [CrossRef]

24. Wilkerson, M.J.; Shuman, W.; Swist, S.; Harkin, K.; Meinkoth, J.; Kocan, A.A. Platelet size, platelet surface-associated IgG, and reticulated platelets in dogs with immune-mediated thrombocytopenia. Vet. Clin. Pathol. 2001, 30, 141-149. [CrossRef] [PubMed]

25. Born, G.V.R.; Cross, M. The aggregation of blood platelets. J. Physiol. 1963, 168, 178-195. [CrossRef]

26. Fuentes, E.; Fuentes, M.; Caballero, J.; Palomo, I.; Hinz, S.; El-Tayeb, A.; Müller, C.E. Adenosine A2A receptor agonists with potent antiplatelet activity. Platelets 2018, 29, 292-300. [CrossRef]

27. Tan, P.; Hao, Y.; Liu, Y.; Peng, K.R.; Ding, S.J. Effects of the main monomer ingredients of Ginkgo biloba extract on phosphodiesterase 3 activity of platelet. Chin. J. Clin. Phys. 2013, 7, 11569-11573.

28. Sepúlveda, C.; Hernández, B.; Burgos, C.F.; Fuentes, E.; Palomo, I.; Alarcón, M. The cAMP/PKA Pathway Inhibits Beta-amyloid Peptide Release from Human Platelets. Neuroscience 2019, 397, 159-171. [CrossRef]

29. Ritchie, J.L.; Alexander, H.D.; Rea, I.M. Flow cytometry analysis of platelet P-selectin expression in whole blood-methodological considerations. Clin. Lab. Haematol. 2000, 22, 359-363. [CrossRef]

30. Walsh, T.G.; Berndt, M.C.; Carrim, N.; Cowman, J.; Kenny, D.; Metharom, P. The role of Nox1 and Nox2 in GPVI-dependent platelet activation and thrombus formation. Redox Biol. 2014, 2, 178-186. [CrossRef]

31. Urra, F.A.; Muñoz, F.; Córdova-Delgado, M.; Ramírez, M.P.; Peña-Ahumada, B.; Rios, M.; Cruz, P.; Ahumada-Castro, U.; Bustos, G.; Silva-Pavez, E. FR58P1a: A new uncoupler of OXPHOS that inhibits migration in triple-negative breast cancer cells via Sirt1/AMPK/ $\beta 1$-integrin pathway. Sci. Rep. 2018, 8, 1-16. [CrossRef]

32. Vilahur, G.; Segalés, E.; Casaní, L.; Badimon, L. A novel anti-ischemic nitric oxide donor inhibits thrombosis without modifying haemodynamic parameters. Thromb. Haemost. 2004, 91, 1035-1043. [CrossRef] [PubMed]

33. Fuentes, F.; Alarcón, M.; Badimon, L.; Fuentes, M.; Klotz, K.-N.; Vilahur, G.; Kachler, S.; Padró, T.; Palomo, I.; Fuentes, E. Guanosine exerts antiplatelet and antithrombotic properties through an adenosine-related cAMP-PKA signaling. Int. J. Cardiol. 2017, 248, 294-300. [CrossRef] 
34. Percie du Sert, N.; Hurst, V.; Ahluwalia, A.; Alam, S.; Avey, M.T.; Baker, M.; Browne, W.J.; Clark, A.; Cuthill, I.C.; Dirnagl, U. The ARRIVE guidelines 2.0: Updated guidelines for reporting animal research. J. Cereb. Blood Flow Metab. 2020, 40, $1769-1777$. [CrossRef] [PubMed]

35. Koupenova, M.; Kehrel, B.; Corkrey, H.; Freedman, J. Thrombosis and platelets: An update. Eur. Heart J. 2017, 38, 785-791. [CrossRef]

36. Harrington, R.A.; Hodgson, P.K.; Larsen, R.L. Antiplatelet therapy. Circulation 2003, 108, e45-e47. [CrossRef] [PubMed]

37. Fox, K.A.A.; Mehta, S.R.; Peters, R.; Zhao, F.; Lakkis, N.; Gersh, B.J.; Yusuf, S. Benefits and risks of the combination of clopidogrel and aspirin in patients undergoing surgical revascularization for non-st-elevation acute coronary syndrome. Circulation 2004, 110, 1202-1208. [CrossRef]

38. Yamaguchi, M.; Hamamoto, R.; Uchiyama, S.; Ishiyama, K. Effects of flavonoid on calcium content in femoral tissue culture and parathyroid hormone-stimulated osteoclastogenesis in bone marrow culture in vitro. Mol. Cell. Biochem. 2007, 303, 83-88. [CrossRef] [PubMed]

39. Yang, B.; Li, X.-P.; Ni, Y.-F.; Du, H.-Y.; Wang, R.; Li, M.-J.; Wang, W.-C.; Li, M.-M.; Wang, X.-H.; Li, L. Protective effect of isorhamnetin on lipopolysaccharide-induced acute lung injury in mice. Inflammation 2016, 39, 129-137. [CrossRef]

40. Choi, Y.H. The cytoprotective effect of isorhamnetin against oxidative stress is mediated by the upregulation of the Nrf2dependent HO-1 expression in C2C12 myoblasts through scavenging reactive oxygen species and ERK inactivation. Gen. Physiol. Biophys. 2016, 35, 145-154. [CrossRef] [PubMed]

41. Zheng, Q.; Tong, M.; Ou, B.; Liu, C.; Hu, C.; Yang, Y. Isorhamnetin protects against bleomycin-induced pulmonary fibrosis by inhibiting endoplasmic reticulum stress and epithelial-mesenchymal transition. Int. J. Mol. Med. 2019, 43, 117-126. [CrossRef]

42. Van der Meijden, P.; Heemskerk, J. Platelet biology and functions: New concepts and clinical perspectives. Nat. Rev. Cardiol. 2019, 16, 166-179. [CrossRef] [PubMed]

43. Augereau, O.; Rossignol, R.; DeGiorgi, F.; Mazat, J.-P.; Letellier, T.; Dachary-Prigent, J. Apoptotic-like mitochondrial events associated to phosphatidylserine exposure in blood platelets induced by local anaesthetics. Thromb. Haemost. Stuttg. 2004, 92, 104-113. [CrossRef] [PubMed]

44. Chi, Y.S.; Jong, H.G.; Son, K.H.; Chang, H.W.; Kang, S.S.; Kim, H.P. Effects of naturally occurring prenylated flavonoids on enzymes metabolizing arachidonic acid: Cyclooxygenases and lipoxygenases. Biochem. Pharm. 2001, 62, 1185-1191. [CrossRef]

45. Yang, J.H.; Kim, S.C.; Shin, B.Y.; Jin, S.H.; Jo, M.J.; Jegal, K.H.; Kim, Y.W.; Lee, J.R.; Ku, S.K.; Cho, I.J.; et al. O-methylated flavonol isorhamnetin prevents acute inflammation through blocking of NF-kB activation. Food Chem. Toxicol. 2013, 59, 362-372. [CrossRef]

46. Li, W.; Chen, Z.; Yan, M.; He, P.; Chen, Z.; Dai, H. The protective role of isorhamnetin on human brain microvascular endothelial cells from cytotoxicity induced by methylglyoxal and oxygen-glucose deprivation. J. Neurochem. 2016, 136, 651-659. [CrossRef]

47. Mitrugno, A.; Rigg, R.A.; Laschober, N.B.; Ngo, A.T.P.; Pang, J.; Williams, C.D.; Aslan, J.E.; McCarty, O.J.T. Potentiation of TRAP6-induced platelet dense granule release by blockade of P2Y12 signaling with MRS2395. Platelets 2018, 29, 383-394. [CrossRef]

48. Clemetson, K.J.; Clemetson, J.M. Platelet collagen receptors. Thromb. Haemost. 2001, 86, 189-197. [CrossRef]

49. Jung, S.-H.; Han, J.-H.; Park, H.-S.; Lee, J.-J.; Yang, S.Y.; Kim, Y.H.; Heo, K.-S.; Myung, C.-S. Inhibition of collagen-induced platelet aggregation by the secobutanolide secolincomolide A from Lindera obtusiloba Blume. Front. Pharmacol. 2017, 8, 560. [CrossRef]

50. Hubbard, G.P.; Wolffram, S.; de Vos, R.; Bovy, A.; Gibbins, J.M.; Lovegrove, J.A. Ingestion of onion soup high in quercetin inhibits platelet aggregation and essential components of the collagen-stimulated platelet activation pathway in man: A pilot study. $\mathrm{Br}$. $\mathrm{J}$. Nutr. 2006, 96, 482-488.

51. Medeiros, R.; Otuki, M.F.; Avellar, M.C.W.; Calixto, J.B. Mechanisms underlying the inhibitory actions of the pentacyclic triterpene $\alpha$-amyrin in the mouse skin inflammation induced by phorbol ester 12-O-tetradecanoylphorbol-13-acetate. Eur. J. Pharmacol. 2007, 559, 227-235. [CrossRef]

52. Fuentes, M.; Sepúlveda, C.; Alarcón, M.; Palomo, I.; Fuentes, E. Buddleja globosa (matico) prevents collagen-induced platelet activation by decreasing phospholipase C-gamma 2 and protein kinase C phosphorylation signaling. J. Trad. Complementary Med. 2018, 8, 66-71. [CrossRef] [PubMed]

53. Mendez, D.; Donoso-Bustamante, V.; Pablo Millas-Vargas, J.; Pessoa-Mahana, H.; Araya-Maturana, R.; Fuentes, E. Synthesis and pharmacological evaluation of acylhydroquinone derivatives as potent antiplatelet agents. Biochem. Pharmacol. 2021, 183, 114341. [CrossRef] [PubMed]

54. Mendez, D.; Urra, F.A.; Millas-Vargas, J.P.; Alarcon, M.; Rodriguez-Lavado, J.; Palomo, I.; Trostchansky, A.; Araya-Maturana, R.; Fuentes, E. Synthesis of antiplatelet ortho-carbonyl hydroquinones with differential action on platelet aggregation stimulated by collagen or TRAP-6. Eur. J. Med. Chem. 2020, 192, 112187. [CrossRef] [PubMed]

55. Nieswandt, B.; Watson, S.P. Platelet-collagen interaction: Is GPVI the central receptor? Blood 2003, 102, 449-461. [CrossRef] [PubMed] 